\title{
The ghost of the great imitator: prognostic factors for poor outcome in syphilitic uveitis
}

\author{
Rafael de Pinho Queiroz ${ }^{1,2,4}$, Daniele Viana Inês ${ }^{1}$, Felipe Telöken Diligenti ${ }^{3}$, Victor Haygert Schnor ${ }^{3}$, \\ Jacobo Melamed ${ }^{3}$, Wesley Ribeiro Campos ${ }^{1,2}$ and Daniel Vítor Vasconcelos-Santos ${ }^{1,2,4^{*}}$
}

\begin{abstract}
Background: Syphilitic uveitis is reemerging globally, may lead to any type of intraocular inflammation, and is potentially sight-threatening. We aim to characterize clinical features and prognostic factors in patients with syphilitic posterior uveitis.

Methods: Retrospective chart review at two tertiary university-based referral centers in Brazil. Clinical data, laboratory results, and treatment outcomes were analyzed. Statistical analysis was performed using Fisher's exact test for categorical variables and Mann-Whitney $U$ test for continuous variables.

Results: Forty-four patients (81 eyes) were consecutively diagnosed with syphilitic posterior uveitis between March 2011 and April 2013.Thirty-one were male (70.5\%) and the mean age was 43.8 years (range 15-81). HIV confection was disclosed in 12 patients (29.3\%). The most prevalent finding was vitritis (85.2\%), followed by retinal involvement (76.4\%) and optic disc abnormalities (63.5\%). After treatment, mean visual acuity improved from 1.2 (20/320) to 0.6 (20/80; median 20/30), but 19 eyes (23.5\%) persisted with $\leq 1.0$ (20/200). Factors associated with final visual acuity $\leq 1.0$ despite therapy were prior use of systemic corticosteroids $(p=0.001)$, higher Venereal Disease Research Laboratory titers $(p=0.004)$, longer duration of symptoms $(p=0.024)$, and worse initial VA $(p<0.001)$.

Conclusions: Syphilitic uveitis is reemerging. Delayed diagnosis and inadvertent use of systemic corticosteroids are potentially modifiable prognostic factors to be considered for possibly improving outcomes.
\end{abstract}

Keywords: Epidemiology, Prognosis, Sexually transmitted diseases, Syphilis, Uveitis

\section{Background}

Syphilis is a multisystemic, potentially sight-threatening disease caused by the spirochete Treponema pallidum. With the advent of penicillin in the middle of last century, global prevalence of syphilis progressively dropped, with parallel decrease in disease morbidity to the central nervous system [1]. However, the incidence of syphilis has now been increasing for more than 15 years,

\footnotetext{
*Correspondence: dvitor@ufmg.br; dvitorvs@gmail.com

Presented in part at the XXXIII Congresso do Hospital São Geraldo, Belo Horizonte, Brazil, on October 31, 2013, and at the 9th International

Symposium on Uveitis, Dublin, Ireland, on August 19, 2016.

'Departamento de Oftalmologia e Otorrinolaringologia, Faculdade de Medicina da Universidade Federal de Minas Gerais, Av. Alfredo Balena 190. Sala 199, Belo Horizonte, MG 30.130-100, Brazil

${ }^{2}$ Hospital São Geraldo/Hospital das Clínicas da Universidade Federal de Minas Gerais, Belo Horizonte, Brazil

Full list of author information is available at the end of the article
}

particularly in association with human immunodeficiency virus (HIV) coinfection and with contemporary changes in sexual practices [2-6].

Syphilis may lead to any type of intraocular inflammation, with distinct forms of syphilitic retinitis being characterized in the last decade [7-9]. However, due to the lack of pathognomonic signs and to the fact that uveitis may be the first (and even sole) manifestation of the disease, a high index of suspicion is essential to allow for prompt and appropriate serologic testing, arriving at a definite diagnosis [10].

The prognosis of syphilitic uveitis is classically regarded as favorable, with good response to adequate antibiotic therapy [3, 11, 12]. Few studies tried to characterize factors possibly associated with worse visual outcome in syphilitic uveitis. These reports, however, included 
relatively small number of patients over long periods of time (up to 30 years) [13-16].

In the context of the reemergence of this old disease and in parallel to other smaller reports [10, 11, 13, 14, 17-19], we aim to investigate clinical features and potential demographic and clinical prognostic factors in a relatively larger series of patients diagnosed with syphilitic posterior uveitis during 2 years at two university-based referral centers in Brazil.

\section{Methods}

After institutional board review and in accordance with the tenets of the Declaration of Helsinki, we retrospectively reviewed charts of patients consecutively diagnosed with posterior syphilitic uveitis from March 2011 to April 2013 at two university-based uveitis referral centers in Brazil. Venereal Disease Research Laboratory (VDRL) and treponema pallidum hemagglutination (TPHA) or fluorescent treponemal antibody absorption (FTA-Abs) assays were routinely performed for all patients. All cases presenting with active posterior uveitis, positive treponemal test results, and favorable response to intravenous penicillin were included, provided that other etiologies were ruled out after appropriate investigations.

Data were collected on age, sex, race, duration of ocular symptoms, affected eye(s), prior use of systemic corticosteroids, best-corrected visual acuity (BCVA), serologic results, HIV coinfection (including CD4 count), cerebral spinal fluid (CSF) analysis, systemic findings, slit-lamp and fundus examination, treatment, and follow-up. BCVA was directly assessed using Early Treatment of Diabetic Retinopathy Study (ETDRS) chart in one center and conventional Snellen chart in the other center, the latter with subsequent conversion of BCVA to LogMAR equivalent.

Statistical analysis was performed using SPSS software version 19 (SPPS, Inc., Chicago, IL, USA) comparing subgroups of eyes attaining final BCVA $\leq 1.0(20 / 200)$ or $>1.0(20 / 200)$. In bilateral cases, the eye with the worst final BCVA was considered for calculation purposes. Categorical variables were compared using Fisher's exact test, and continuous variables were compared using Mann-Whitney $U$ test. A $p$ value of $<0.05$ was considered statistically significant.

\section{Results}

We included forty-four patients (81 eyes) diagnosed with active syphilitic posterior uveitis between March 2011 and April 2013. Twenty-three (52.3\%) were seen at the Uveitis Unit of Hospital São Geraldo/Hospital das Clínicas da Universidade Federal de Minas Gerais between April 2011 and April 2013 and 21 (47.7\%) at the Uveitis Unit of Hospital de Clínicas da Universidade Federal do Rio Grande do Sul, between March 2011 and February 2013.
The majority of patients were male (70.5\%), with a mean age of 43.8 years (range 15-81). Intraocular inflammation was bilateral in 37 patients (84.1\%) and unilateral in 7 (15.9\%).

At presentation, 11 patients (25.0\%) displayed cutaneous lesions suggestive of secondary syphilis and one (2.3\%) had genital lesions. All, except three patients, had a positive VDRL, with titers ranging from 1:4 to 1:4096 (median 1/64). Treponemal test results could not be retrieved for five patients, but these all had high VDRL titers (ranging from 1:64 to 1:256).

Duration of ocular symptoms before presentation ranged from 4 to 720 days (mean 104.5 days; median 38.5 days). Nine patients (20.5\%) had inadvertently received systemic corticosteroids (oral or parenteral) prior to the definite diagnosis. Twelve patients (29.3\%) were HIV-positive, and three patients had unknown HIV status. CD4 count was available for nine patients, with a mean of 260.1 cells $/ \mathrm{mm}^{3}$ (range $50-569$ ).

Lumbar puncture (LP) was performed in 33 patients (75\%), with $23(69.7 \%)$ showing CSF changes such as positive VDRL, pleocytosis, and/or hyperproteinemia. Among HIV-coinfected patients, 10 underwent LP, of which nine (90\%) had CSF abnormalities, in contrast to CSF positivity of $61.9 \%$ among those HIV-negative.

BCVA at presentation ranged from $0.0(20 / 20)$ to no light perception [mean 1.2 (20/320); median 1.0 (20/ 200)]. Slit lamp examination and fundus examination showed vitritis in 69 eyes (85.2\%). Fundus examination was precluded due to dense vitritis in three eyes of two patients, and these were excluded from the analysis of optic disc and retinal, choroidal, and retinal vascular lesions. Initial B-scan, however, showed attached retinas in all of them. Ocular features, including initial and final BCVA, fundus examination at presentation, and complications, are summarized in Table 1 . Of note, 11 eyes (13.6\%) of eight patients (18.2\%) presented with features of acute syphilitic posterior placoid chorioretinitis.

All patients were treated with intravenous benzylpenicillin 4 million IU q4h for 12-21 days (mean 15.1; median 14 days), except one patient, who initially presented with posterior placoid chorioretinitis at our emergency care unit, documented by color fundus photography, but by the time of the consultation at the Uveitis Unit, intraocular inflammation had spontaneously resolved. He was then treated with three doses of benzathine penicillin 2.4 $\mathrm{M}$ units. A tapering regimen of systemic corticosteroid was also prescribed to 33 patients (75\%).

Intraocular inflammation resolved after therapy in all patients (mean 8.3 months, median 7 months, range 1-24 months). Final BCVA ranged from 0.0 $(20 / 20)$ to no light perception [mean $0.6(20 / 80)$; median $0.2(20 / 30)]$. Nineteen eyes (23.5\%) had BCVA $\leq$ $1.0(20 / 200)$ at last follow-up visit, and 54 eyes (66.7\%) 
Table 1 Ocular features and complications in 81 eyes of 44 patients with syphilitic posterior uveitis

\begin{tabular}{ll}
\hline & $N(\%)$ \\
\hline BCVA at presentation & \\
NLP & $4 / 81(5.0 \%)$ \\
LP-20/200 & $44 / 81(54.3 \%)$ \\
$20 / 160-20 / 63$ & $10 / 81(12.3 \%)$ \\
20/60-20/20 & $23 / 81(28.4 \%)$ \\
Final BCVA & \\
NLP & $4 / 81(5.0 \%)$ \\
LP-20/200 & $15 / 81(18.5 \%)$ \\
20/160-20/63 & $8 / 81(9.8 \%)$ \\
20/60-20/20 & $54 / 81(66.7 \%)$ \\
Fundus examination & \\
Vitritis & $69 / 81(85.2 \%)$ \\
Optic disc abnormalities & $47 / 74(63.5 \%)$ \\
Retinal involvement & $60 / 78(76.9 \%)$ \\
Retinal vasculitis & $36 / 78(46.2 \%)$ \\
Necrotizing retinitis & $17 / 78(21.8 \%)$ \\
Posterior placoid chorioretinitis & $11 / 77(14.3 \%)$ \\
Non-necrotizing retinitis & $11 / 78(14.1 \%)$ \\
Punctate inner retinal lesions & $6 / 78(7.7 \%)$ \\
Others & $9 / 78(11.5 \%)$ \\
Ocular complications & \\
Cataract & $4 / 81(4.9 \%)$ \\
Epiretinal membrane & $10 / 81(12.3 \%)$ \\
Retinal detachment & $4 / 81(4.9 \%)$ \\
Optic atrophy & $14 / 81(17.3 \%)$ \\
Others & \\
\hline BCVA bestcoret & \\
\hline
\end{tabular}

$B C V A$ best-corrected visual acuity, NLP no light perception, $L P$ light perception

had final BCVA of $\geq 0.5(20 / 60)$. Of the 37 bilateral cases, six $(16.2 \%)$ ended up legally blind, with a final BCVA $\leq 1.0$ (20/200) in the better eye. Ocular complications developed in 40 eyes (49.4\%) of 31 patients (70.4\%), with the most prevalent being retinal detachment (RD) in 10 eyes (Table 1).

Final BCVA $\leq 1.0(20 / 200)$ was statistically associated with longer duration of symptoms before diagnosis $(p=$ $0.024)$, prior inadvertent use of systemic corticosteroids $(p=0.001)$, higher VDRL titers $(p=0.004)$, and worse initial BCVA $(p<0.0001)$, but not with sex $(p=0.131)$ or HIV coinfection $(p=0.300)$. Older age and presence of necrotizing retinochoroiditis were shown not to be statistically significant, but might be related to poor outcomes-Table 2.

In addition, inadvertent use of systemic corticosteroids and VDRL titers seem not to be correlated, when comparing the group of patients who received and did not
Table 2 Prognostic factors associated with syphilitic posterior uveitis in 44 patients

\begin{tabular}{|c|c|c|c|}
\hline & $\begin{array}{l}\text { Final BCVA } \\
<1.0(20 / 200)\end{array}$ & $\begin{array}{l}\text { Final BCVA } \\
>1.0(20 / 200)\end{array}$ & $p$ value \\
\hline \multicolumn{4}{|l|}{ Sex } \\
\hline Male & $11(84.6)$ & $20(64.5)$ & \multirow[t]{2}{*}{$0.282^{*}$} \\
\hline Female & $2(15.4)$ & $11(35.5)$ & \\
\hline Age (mean per eye) & $51.7 \pm 18.3$ & $40.5 \pm 15.9$ & $0.070^{* *}$ \\
\hline \multicolumn{4}{|l|}{ HIV coinfection } \\
\hline Positive & $5(38.5)$ & $7(25.0)$ & \multirow[t]{2}{*}{$0.469^{*}$} \\
\hline Negative & $8(61.5)$ & $21(75.0)$ & \\
\hline Median VDRL titer & $\begin{array}{l}1 / 512 \\
{[0-4096]}\end{array}$ & $\begin{array}{l}1 / 64 \\
{[0-4096]}\end{array}$ & $0.004^{* *}$ \\
\hline \multicolumn{4}{|c|}{ Prior inadvertent use of systemic steroids } \\
\hline Yes & $7(53.8)$ & $2(6.4)$ & \multirow[t]{2}{*}{$0.001^{*}$} \\
\hline No & $6(46.2)$ & $29(93.6)$ & \\
\hline \multicolumn{4}{|c|}{ Presence of necrotizing retinochoroiditis } \\
\hline Yes & $6(46.2)$ & $5(16.1)$ & \multirow[t]{2}{*}{$0.057^{*}$} \\
\hline No & $7(53.8)$ & $26(83.9)$ & \\
\hline $\begin{array}{l}\text { Mean time of symptoms } \\
\text { before diagnosis (days) }\end{array}$ & $176.8 \pm 250.2$ & $74.8 \pm 133.1$ & $0.024^{* *}$ \\
\hline Mean initial BCVA (LogMAR) & $2.1 \pm 0.6$ & $1.1 \pm 0.7$ & $<0.001^{* *}$ \\
\hline
\end{tabular}

Continuous variables are expressed as median [range] or mean \pm standard deviation

Categorical variables are expressed as absolute number (\%)

$B C V A$ Best-corrected visual acuity

*Fisher's exact test

**Mann-Whitney $U$ test

receive corticosteroids prior to the diagnosis $(p=0.56)$. Furthermore, high VDRL titers $(\geq 1 / 128)$ were associated with poor outcome [odds ratio 10.86 (CI 2.2-83.9)], as well as use of systemic corticosteroids with no antibiotic coverage [odds ratio 15.43 (CI 2.7-131.2)].

\section{Discussion}

After a steady decline during the 1990s, the global incidence of syphilis is again increasing [20], with ocular manifestations being on the rise, especially among men [2-6]. Posterior uveitis is the most common ocular manifestation [12, 21, 22], regardless of HIV status. Herein, we present data from 44 patients with syphilitic posterior uveitis consecutively seen at two referral centers in Brazil over a period of 2 years (average of 22 patients/year), in contrast to other published series collecting cases over much longer periods of time, with the exception of the study by Mathew et al. [11] (Table 3). In addition to relevant demographic and clinical data, we also identified potentially modifiable prognostic factors, helping to raise awareness of this ancient, but intriguing disease. Agreeing with the literature $[10,11,13-15,17-19,21-23]$, uveitis occurred more frequently in middle-aged men, being bilateral in most patients (84.1\%). HIV coinfection was present in nearly one 
Table 3 Comparison of published series on syphilitic uveitis

\begin{tabular}{|c|c|c|c|c|c|}
\hline Reference & Country & Number of centers & Number of patients & Period (no. of years) & No. of patients/yeart \\
\hline Present series & Brazil & 2 & 44 & $2011-2013$ (2) & 22 \\
\hline Hoogewoud et al. [24] & France & 2 & 66 & 2003-2016 (14) & 4.7 \\
\hline Bollemeijer et al. [15] & Netherlands & 5 & 85 & 1984-2013 (29) & 2.9 \\
\hline Tsuboi et al. [27] & Japan & 1 & 20 & 1997-2015 (18) & 1.1 \\
\hline Zhang et al. [16] & China & 1 & 15 & 2012-2015 (3) & 5 \\
\hline Shen et al. [28] & China & 1 & 13 & 2009-2014 (5) & 2.6 \\
\hline Carbonnière et al. [29] & France & 1 & 27 & 2000-2013 (13) & 2.1 \\
\hline Lee et al. [30] & USA & 1 & 16 & 2008-2014 (6) & 2.7 \\
\hline Moradi et al. [19] & USA & 1 & 35 & 1984-2014 (20) & 1.75 \\
\hline Northey et al. [17] & Australia & 1 & 25 & 2007-2012 (5) & 5 \\
\hline Yap et al. [31] & Singapore & 1 & 12 & 2004-2009 (5) & 2.4 \\
\hline Fonollosa et al. [14] & Spain & 8 & 50 & 2000-2012 (12) & 4.2 \\
\hline Mathew et al. [11] & United Kingdom & National & 41 & 2009-2011 (2) & 20.5 \\
\hline Yang et al. [10] & China & 1 & 19 & 2004-2011 (7) & 2.7 \\
\hline Li et al. [32] & USA & 1 & 13 & 1991-2009 (18) & 0.7 \\
\hline Balaskas et al. [13] & Switzerland & 1 & 26 & 1999-2009 (10) & 2.6 \\
\hline Fonollosa et al. [5] & Spain & 2 & 12 & 2005-2007 (2) & 6 \\
\hline Anshu et al. [6] & Singapore & 1 & 22 & 1995-2006 (11) & 2 \\
\hline Parc et al. [33] & France & 1 & 10 & 2001-2004 (3) & 3.3 \\
\hline Doris [2] & England & 1 & 6 & $2004(1)$ & 6 \\
\hline Chao et al. [3] & USA & 1 & 4 & $2005(1)$ & 4 \\
\hline Tran et al. [34] & France & 1 & 12 & 2001-2003 (2) & 6 \\
\hline Ormerod et al. [35] & USA & 1 & 21 & 1990-1993 (3) & 7 \\
\hline Browning et al. [18] & USA & 1 & 14 & 1986-1999 (13) & 1.1 \\
\hline Villanueva et al. [36] & USA & 1 & 20 & 1993-1996 (3) & 6.7 \\
\hline Shalaby et al. [37] & USA & 1 & 13 & 1983-1995 (12) & 1.1 \\
\hline Barile and Flynn [38] & USA & 1 & 24 & 1989-1994 (5) & 4.8 \\
\hline Tamesis and Foster [39] & USA & 1 & 25 & 1983-1989 (6) & 4.2 \\
\hline Schlaegel and Rao [40] & USA & 1 & 28 & 1970-1980 (10) & 2.8 \\
\hline
\end{tabular}

† Total number of patients included in each study divided by the study period in years

third of the patients, highlighting the importance of HIV testing in individuals with syphilis. Also in line with other reports [14, 21, 22], CSF changes consistent with neurosyphilis were more common in HIV-positive patients than in immunocompetent ones.

Our patients were managed with intravenous benzylpenicilin and adjunctive corticosteroids. Visual prognosis following treatment was good, with the majority reaching final BCVA $\geq 0.5(20 / 60)$. A significant proportion of our patients, however, persisted with decreased BCVA due to ocular complications, mainly $\mathrm{RD}$ and optic atrophy. Factors associated with a poorer prognosis (BCVA $\leq 1.0$ ) included prior inadvertent use of systemic steroids, delayed diagnosis, higher VDRL titers, and worse initial BCVA. Some of these associations have been suggested in earlier reports [14-16, 19, 24] and highlight the importance of early recognition of this entity, invariably performing adequate serological tests for syphilis in all patients presenting with uveitis, for prompt institution of adequate treatment. Interestingly, our finding of higher VDRL titers being associated with worse prognosis may be related to increased treponemal load and disease activity [25]. HIV coinfection was not associated with a worse visual prognosis, similarly to other studies [11, 14, 15, 17, 19]. A recent report from China, however, has found this association [10].

A prospective study from the UK published by Mathew et al. [11] with a comparable number of patients over a similar time span reports different results and final outcomes, when compared to the present series. 
The overall better prognosis in the British paper might be related to an earlier diagnosis at the early phases of secondary syphilis. This is highlighted by the shorter duration of symptoms before diagnosis, better mean VA at presentation, and the fact that the study looked at ocular presentation in early syphilis. Our series includes a larger number of bilateral cases and some patients with low and a few with even negative VDRL titers, indicating that syphilis might have been present and undiagnosed in our patients for a longer period of time. This late presentation, in addition to prior use of corticosteroids and the exclusion of subjects with anterior uveitis only, might explain, at least in part, our worse outcome when compared to Mathew et al. [11].

Recently, a large retrospective study analyzed prognostic factors for syphilitic uveitis [24] as predictors of ophthalmological recovery 1 month after treatment onset. The authors could find that baseline BCVA and initial improvement at 1 week were associated with recovery at 1 month and periocular dexamethasone injections and methylprednisolone pulses negatively affected the outcomes. However, complications might still arise after 1 month of treatment onset, as previously reported [26].

Our study is limited by its retrospective design and relatively short follow-up. On the other hand, the concentration of cases over a relatively short period of time (average of 22 patients/year), when compared to previous reports (Table 3), is to be considered.

In conclusion, syphilitic uveitis is reemerging globally. Delayed diagnosis and inadvertent use of systemic corticosteroids are potentially modifiable prognostic factors to be considered for possibly improving outcomes. Proper recognition of its forms of presentation, prognostic factors, and complications may be helpful for better diagnosis/management of this fascinating disorder.

\section{Abbreviations}

BCVA: Best-corrected visual acuity; CSF: Cerebral spinal fluid; ETDRS: Early Treatment of Diabetic Retinopathy Study; FTA-Abs: Fluorescent treponemal antibody absorption; HIV: Human immunodeficiency virus; RD: Retinal detachment; TPHA: Treponema pallidum hemagglutination assay; VDRL: Venereal Disease Research Laboratory

\section{Acknowledgements}

Not applicable

\section{Funding}

There are no funding sources for this research

\section{Availability of data and materials}

The datasets used and/or analysed during the current study are available from the corresponding author on reasonable request.

\section{Authors' contributions}

RQ made contributions on the conception and design; acquisition, analysis, and interpretation of data; and drafting of the article and revising it. DI made contributions on the acquisition of data and revision of the article. FD made contributions on the acquisition, analysis, and interpretation of data and revision of the article. VS made contributions on the acquisition of data and revision of the article. JM and WC made contributions on the analysis and interpretation of data and revision of the article. DVS made contributions on conception and design; acquisition, analysis, and interpretation of data; and revision of the article. All authors read and approved the final manuscript.

Ethics approval and consent to participate

This study was approved by the ethics committee "Comitê de Ética em Pesquisa (COEP) da Universidade Federal de Minas Gerais"

Consent for publication

Not applicable

\section{Competing interests}

The authors declare that they have no competing interests.

\section{Publisher's Note}

Springer Nature remains neutral with regard to jurisdictional claims in published maps and institutional affiliations.

\section{Author details}

1Departamento de Oftalmologia e Otorrinolaringologia, Faculdade de Medicina da Universidade Federal de Minas Gerais, Av. Alfredo Balena 190. Sala 199, Belo Horizonte, MG 30.130-100, Brazil. ${ }^{2}$ Hospital São Geraldo/ Hospital das Clínicas da Universidade Federal de Minas Gerais, Belo Horizonte, Brazil. ${ }^{3}$ Hospital de Clínicas de Porto Alegre - Universidade Federal do Rio Grande do Sul, Porto Alegre, Brazil. ${ }^{4}$ Programa de Pós-graduação em Ciências da Saúde - Infectologia e Medicina Tropical UFMG, Belo Horizonte, Brazil.

Received: 7 October 2018 Accepted: 8 January 2019

Published online: 18 January 2019

\section{References}

1. Centers for Disease Control and Prevention (2012) Sexually transmitted disease surveillance 2011. U.S Department of Health and Human Services, Atlanta

2. Doris JP, Saha K, Jones NP, Sukthankar A (2006) Ocular syphilis: the new epidemic. Eye 20:703-705

3. Chao JR, Khurana RN, Fawzi AA et al (2006) Syphilis: reemergence of an old adversary. Ophthalmology 113:2074-2079 https://doi.org/10.1016/j.ophtha. 2006.05.048

4. González-López JJ, Guerrero MLF, Luján R et al (2009) Factors determining serologic response to treatment in patients with syphilis. Clin Infect Dis 49: 1505-1511 https://doi.org/10.1086/644618

5. Fonollosa A, Giralt J, Pelegrín L et al (2009) Ocular syphilis—back again: understanding recent increases in the incidence of ocular syphilitic disease. Ocul Immunol Inflamm 17:207-212 https://doi.org/10.1080/09273940902741709

6. Anshu A, Cheng CL, Chee S-P (2008) Syphilitic uveitis: an Asian perspective. Br J Ophthalmol 92:594-597 https://doi.org/10.1136/bjo.2007.133843

7. Wickremasinghe S, Ling C, Stawell R et al (2009) Syphilitic punctate inner retinitis in immunocompetent gay men. Ophthalmology 116:1195-1200 https://doi.org/10.1016/j.ophtha.2008.12.055

8. Geraets RL, Dodds EM, Echandi LV et al (2010) Superficial retinal precipitates in patients with syphilitic retinitis. Retina 30:1135-1143

9. Pichi F, Ciardella AP, Cunningham ET Jr et al (2014) Spectral domain optical coherence tomography findings in patients with acute syphilitic posterior placoid chorioretinopathy. Retina 34:373-384

10. Yang P, Zhang N, Li F et al (2012) Ocular manifestations of syphilitic uveitis in Chinese patients. Retina 32:1906-1914

11. Mathew RG, Goh BT, Westcott MC (2014) British Ocular Syphilis Study (BOSS): 2-year national surveillance study of intraocular inflammation secondary to ocular syphilis. Investig Opthalmology Vis Sci 55:5394 https:// doi.org/10.1167/iovs.14-14559

12. Agostini FA, Queiroz RP, Azevedo DOM et al (2018) Intravenous ceftriaxone for syphilitic uveitis. Ocul Immunol Inflamm 26:1059-65 https://doi.org/10. 1080/09273948.2017.1311926

13. Balaskas K, Sergentanis TN, Giulieri S, Guex-Crosier Y (2011) Analysis of significant factors influencing visual acuity in ocular syphilis. Br J Ophthalmol 95:1568-1572 https://doi.org/10.1136/bjo.2010.194498

14. Fonollosa A, Martinez-Indart L, Artaraz J, et al (2014) Clinical manifestations and outcomes of syphilis-associated uveitis in northern Spain. Ocul Immunol Inflamm 24:147-152. https://doi.org/10.3109/09273948.2014. 943349 
15. Bollemeijer JG, Wieringa WG, Missotten TO, et al (2016) Clinical manifestations and outcome of syphilitic uveitis clinical outcomes of syphilitic uveitis. Invest Ophthalmol Vis Sci 57:404-411

16. Zhang R, Qian J, Guo J et al (2016) Clinical manifestations and treatment outcomes of syphilitic uveitis in a Chinese population. J Ophthalmol 2016:1-8 https://doi.org/10.1155/2016/2797028

17. Northey LC, Skalicky SE, Gurbaxani A, McCluskey PJ (2015) Syphilitic uveitis and optic neuritis in Sydney, Australia. Br J Ophthalmol 99:1215-1219 https://doi.org/10.1136/bjophthalmol-2014-306168

18. Browning DJ (2000) Posterior segment manifestations of active ocular syphilis, their response to a neurosyphilis regimen of penicillin therapy, and the influence of human immunodeficiency virus status on response. Ophthalmology 107:2015-2023

19. Moradi A, Salek S, Daniel E et al (2015) Clinical features and incidence rates of ocular complications in patients with ocular syphilis. Am J Ophthalmol 159:334-343.e1 https://doi.org/10.1016/j.ajo.2014.10.030

20. Aldave AJ, King JA, Cunningham ET Jr (2001) Ocular syphilis. Curr Opin Ophthalmol 12:433-441

21. Amaratunge BC, Camuglia JE, Hall AJ (2010) Syphilitic uveitis: a review of clinical manifestations and treatment outcomes of syphilitic uveitis in human immunodeficiency virus-positive and negative patients. Clin Exp Ophthalmol 38:68-74 https://doi.org/10.1111/j.1442-9071.2010.02203.x

22. Tucker JD, Li JZ, Robbins GK et al (2011) Ocular syphilis among HIV-infected patients: a systematic analysis of the literature. Sex Transm Infect 87:4-8 https://doi.org/10.1136/sti.2010.043042

23. Balba GP, Kumar PN, James AN et al (2006) Ocular syphilis in HIV-positive patients receiving highly active antiretroviral therapy. Am J Med 119:448. e21-448.e25 https://doi.org/10.1016/..amjmed.2005.11.016

24. Hoogewoud F, Frumholtz L, Loubet $P$, et al (2017) Prognostic factors in syphilitic uveitis. Ophthalmology 59;27. https://doi.org/10.1016/j.ophtha. 2017.06.003.

25. (2010) Centers for Disease Control and Prevention. Sexually transmitted diseases treatment guidelines. MMWR Morb Mortal Wkly Rep 59:27

26. Queiroz R de P, Diniz AV, Vasconcelos-Santos DV (2016) Fulminant proliferative vitreoretinopathy in syphilitic uveitis. J Ophthalmic Inflamm Infect 6:6 https://doi.org/10.1186/s12348-016-0075-2

27. Tsuboi M, Nishijima T, Yashiro S et al (2016) Prognosis of ocular syphilis in patients infected with HIV in the antiretroviral therapy era. Sex Transm Infect 92:605-610 https://doi.org/10.1136/sextrans-2016-052568

28. Shen J, Feng L, Li Y (2015) Ocular syphilis: an alarming infectious eye disease. Int J Clin Exp Med 8:7770

29. Carbonnière C, Couret C, Guillouzouic A et al (2015) Syphilis oculaire : étude rétrospective de 27 cas au CHU de Nantes (France) de 2000 à 2013. Rev Méd Interne 36:722-727 https://doi.org/10.1016/j.revmed.2015.07.008

30. Lee SY, Cheng V, Rodger D, Rao N (2015) Clinical and laboratory characteristics of ocular syphilis: a new face in the era of HIV co-infection. J Ophthalmic Inflamm Infect 5(1):56 https://doi.org/10.1186/s12348-015-0056-x

31. Yap SC, Tan YL, Chio MTW, Teoh SC (2014) Syphilitic uveitis in a Singaporean population. Ocul Immunol Inflamm 22:9-14 https://doi.org/10. 3109/09273948.2013.829106

32. Li JZ, Tucker JD, Lobo A et al (2010) Ocular syphilis among HIV-infected individuals. Clin Infect Dis 51:468-471 https://doi.org/10.1086/654797

33. Parc CE, Chahed S, Patel SV, Salmon-ceron D (2007) Manifestations and treatment of ocular syphilis during an epidemic in France. Sex Transm Dis 34:553-556 https://doi.org/10.1097/01.olq.0000253385.49373.1a

34. Tran THC, Cassoux N, Bodaghi B et al (2005) Syphilitic uveitis in patients infected with human immunodeficiency virus. Graefes Arch Clin Exp Ophthalmol 243:863-869 https://doi.org/10.1007/s00417-005-1137-6

35. Ormerod LD, Puklin JE, Sobel JD (2001) Syphilitic posterior uveitis: correlative findings and significance. Clin Infect Dis 32:1661-1673

36. Villanueva AV, Sahouri MJ, Ormerod LD et al (2000) Posterior uveitis in patients with positive serology for syphilis. Clin Infect Dis 30:479-485

37. Shalaby IA, Dunn JP, Semba RD, Jabs DA (1997) Syphilitic uveitis in human immunodeficiency virus-infected patients. Arch Ophthalmol 115:469-473

38. Barile GR, Flynn TE (1997) Syphilis exposure in patients with uveitis. Ophthalmology 104:1605-1609

39. Tamesis RR, Foster CS (1990) Ocular syphilis. Ophthalmology 97:1281-1287

40. Schlaegel TF, Rao SF (1982) A review (1970-1980) of 28 presumptive cases of syphilitic uveitis. Am J Ophthalmol 93:412-414

\section{Submit your manuscript to a SpringerOpen ${ }^{\circ}$ journal and benefit from:}

- Convenient online submission

- Rigorous peer review

- Open access: articles freely available online

- High visibility within the field

- Retaining the copyright to your article

Submit your next manuscript at $\boldsymbol{\nabla}$ springeropen.com 